\title{
Simulação interativa do interferômetro de Michelson usando o GeoGebra
}

\author{
Interactive simulation of Michelson interferometer using GeoGebra \\ Nildo Loiola Dias ${ }^{1}$, Giselle dos Santos Castro $^{1}$, Afrânio de Araújo Coelho*1] \\ ${ }^{1}$ Universidade Federal do Ceará, Departamento de Física, Fortaleza, CE, Brasil.
}

Recebido em 03 de junho de 2021. Revisado em 11 de julho de 2021. Aceito em 27 de julho de 2021.

\begin{abstract}
Neste trabalho apresentamos uma simulação do interferômetro de Michelson que foi concebido originalmente por A. A. Michelson para determinar a velocidade da Terra em relação ao éter. A simulação foi criada utilizando o programa GeoGebra para ser utilizada como atividade remota em substituição às aulas experimentais durante o isolamento social imposto pela pandemia de Covid-19. A simulação desenvolvida permite a determinação do comprimento de onda da luz para três cores diferentes bem como a determinação dos índices de refração de quatro gases. Semelhante ao experimento real realizado com equipamentos direcionados para laboratórios de ensino de física, o interferômetro de Michelson simulado apresenta resultados com erros de medições de mesma natureza dos apresentados nas práticas presenciais feitas no laboratório. Os relatórios de práticas produzidos pelos alunos que utilizaram a simulação nos levam a acreditar que a simulação representa uma boa alternativa ao experimento real quando o mesmo não pode ser realizado.
\end{abstract}

Palavras-chave: GeoGebra, interferômetro de Michelson, simulação.

In this work we present a simulation of the Michelson interferometer that was originally conceived by A. A. Michelson to determine the speed of the earth in relation to the aether. The simulation was created using the GeoGebra software to be used as a remote activity to replace the experimental classes during the social isolation imposed by the Covid-19 pandemic. The simulation developed allows the determination of the wavelength of light for three different colors as well as the determination of the refractive indices of four gases. Similar to the real experiment carried out with equipment aimed at physics teaching laboratories, the simulated Michelson interferometer presents results with measurement errors of the same nature as those presented in the classroom practices performed in the laboratory. The practice reports produced by the students who used the simulation lead us to believe that the simulation represents a good alternative to the real experiment when it cannot be carried out.

Keywords: GeoGebra, Michelson interferometer, simulation.

\section{O GeoGebra}

Nos dias atuais, várias simulações voltadas ao ensino de física estão disponíveis na Internet, como as elaboradas pelo projeto Physics Education Technology (PhET) [1]. No entanto, pode acontecer que nenhuma das simulações atinja especificamente um determinado objetivo pedagógico pretendido por algum professor de física. Neste contexto, o professor poderá ter o desejo de elaborar suas próprias simulações. Felizmente, certos ambientes computacionais facilitam bastante este processo ao tornar mais amigável a elaboração de simulações computacionais. Podemos citar ambientes como o Scratch [2], o Easy Javascript Simulations [3, 4] e o Modellus [5, 6] como exemplos. Neste trabalho, iremos apresentar brevemente uma outra plataforma igualmente acessível aos professores para a elaboração de simulações, o GeoGebra, e uma simulação desenvolvida na mesma. Vários tutoriais que ajudam a manusear o GeoGebra estão disponíveis

\footnotetext{
* Endereço de correspondência: afranio@fisica.ufc.br
}

em seu sítio eletrônico oficial bem como em canais do YouTube [7, 8].

GeoGebra é um programa livre que combina geometria interativa, álgebra, cálculo e estatística em um aplicativo fácil de usar para todos os níveis de educação matemática e científica. Ele está traduzido em seus menus e comandos em 50 idiomas diferentes, inclusive o português. A comunidade do GeoGebra envolve milhões de pessoas e centenas de países que inclui uma rede global de professores e alunos, permitindo suporte localizado para aprendizagem e melhorias na educação matemática. GeoGebra faz parte de uma organização empresarial e filantrópica sem fins lucrativos. Apesar de voltado à educação matemática, com o GeoGebra é possível elaborar simulações interativas voltadas às ciências, notadamente à Química e à Física. No caso desta última, uma busca por materiais didáticos no sítio oficial do Geogebra [9] pela palavra chave physics fará apresentar centenas de simulações e animações criadas por terceiros voltados ao ensino de mecânica, eletricidade e ótica, todas disponíveis para baixar. Como 
exemplo, indicamos as simulações desenvolvidas por Tom Walsh [10], um professor estadunidense de física do ensino médio. Walsh [1] descreve bem o efeito pedagógico que a modelagem computacional promove na aprendizagem de física:

Uma das minhas coisas favoritas sobre a criação de simulações de física no GeoGebra é que muitas vezes consigo um entendimento mais profundo de um tópico ou fenômeno através da criação de uma simulação nele (Walsh, p. 317, 2017).

Sistemas físicos podem ser simulados através de ferramentas geométricas e seus comportamentos podem ser expressos graficamente por meio de alguma função matemática, e toda essa esquematização pode ser visualizada, ou por meio de ajustes em alguma variável ou em termos de sucessivas variações de um ou mais parâmetros. A construção e a sequente observação à medida que o sistema evolui em função desses parâmetros possibilita ordenar pensamentos aleatórios que emergem de modo a consolidar o conhecimento sobre o sistema em questão [12]. A capacidade de relacionar uma expressão algébrica a uma representação geométrica, em que modificações nas variáveis e/ou termos promovem mudanças na estrutura e/ou localização de um objeto geométrico qualquer, faz do GeoGebra um recurso didático apreciável. Através de um processo de programação acessível, o professor pode desenvolver aulas e atividades que podem proporcionar uma melhor compreensão ao aluno. A modelagem permite criar simulações onde objetos interativos podem ser facilmente manuseados pelo aluno. Isto viabiliza uma atuação direta do aluno em objetos geométricos concretos como pontos, segmentos, polígonos, vetores, etc, antes explorados de forma puramente simbólica. Neste sentido, uma abordagem de ensino baseada no uso de simulações computacionais pode promover uma aprendizagem em consonância com um processo construtivista [13]. Com base nessa percepção, oferecemos à comunidade de ensino de física uma simulação voltada ao ensino de ótica e de física moderna, programada integralmente com o GeoGebra Script.

Como as outras plataformas computacionais citadas acima, o GeoGebra pode ser instalado nos principais sistemas operacionais para computadores em voga além de dispositivos móveis (tablets e smartphones). GeoGebra pode ainda ser utilizado diretamente pela Internet por meio de seu sítio oficial [14. Sua instalação em dispositivos móveis oferece a oportunidade do aluno apropriar-se do conhecimento de física e de matemática por meio de um dispositivo que está, cada vez mais, a tornar-se onipresente. Com isso, o professor pode realizar atividades na sala de aula ou remotamente que se apoiem em simulações animadas em smartphones, na palma da mão de seu aluno [15].
Diferentemente de outros ambientes computacionais voltados ao ensino, o GeoGebra permite a elaboração de desenhos geométricos com excelente qualidade e precisão, com interface gráfica geométrica e algébrica simultânea, passível de ser editada em cores, estilos e layouts. Também permite a elaboração de gráficos e o manuseio de planilhas e conta com recursos sofisticados de cálculo matemático como um sistema de álgebra computacional (Computer Algebra System-CAS). Além disso, o que torna este aplicativo atraente para o ensino de física é a possibilidade de realizar animações ou simulações. Enquanto a animação apenas apresenta movimentos e/ou sons de objetos, a simulação é um ambiente de interação com o usuário [16], em que é possível, por exemplo, por meio de botões de controle, caixas de seleção, controles deslizantes - o que podemos chamar de controles de interatividade, e esses recursos são disponíveis no GeoGebra, sendo programáveis e livres para serem organizados em tela conforme interesses pedagógicos do professor. Com efeito, objetos geométricos criados no ambiente, bem como imagens importadas, podem ser animados segundo a evolução automática de parâmetros (animation) e de programação (scripting). A linguagem de programação, o GeoGebra Script, é própria ao ambiente e de alto nível, no sentido de que é extremamente amigável com o usuário. Desta forma, o usuário não necessita de conhecimento em nenhuma linguagem usual de programação. No entanto, o GeoGebra permite a escrita de códigos em JavaScript caso o usuário deseje em vez de utilizar seu código nativo.

O Geogebra permite salvar em seu sítio oficial as simulações elaboradas no programa, instalado em um computador ou dispositivo móvel. Com efeito, o usuário pode criar um ambiente próprio neste sítio onde ele possa carregá-lo com várias simulações. Este recurso é extremamente interessante para os professores, pois estes podem acessar e disponibilizar suas simulações diretamente pela Internet. Neste ambiente, o professor pode incluir atividades por meio de vários recursos, como vídeos, imagens, arquivos, acessos a páginas na Internet, etc. Dentre estes recursos, vale ressaltar a possibilidade de incluir notas de aula por meio de um quadro branco digital [17] que permite inserir equações, gráficos, desenhos e tantos outros recursos, além de construções geométricas e animações criadas no ambiente de trabalho do GeoGebra. Nesta lousa digital, o professor pode manipular expressões algébricas de maneira similar à forma tradicional de calcular, ou seja, servindo-se do sistema CAS embutido no GeoGebra.

Apesar da ampla difusão do GeoGebra mundo afora, especialmente em educação matemática, e de diversas aplicações voltadas ao ensino de física, geografia e química, ainda há poucos artigos científicos, painéis e apresentações em congressos que tratem dos impactos pedagógicos das aplicações didáticas deste ambiente computacional em aulas de física ao nível da educação básica, bem como do ensino superior [18]. Em termos 
de materiais elaborados com base na construção do pensamento lógico a partir da programação para simular qualquer comportamento físico em plataformas computacionais, independente de qual seja, no sentido de expor as condições de contorno do sistema em linguagem de programação, ainda é muito mais escasso, e por vezes, deficiente.

Diante das plataformas de modelagem matemática aplicadas ao ensino, tais como aquelas elencadas acima, colocamos o seguinte questionamento: quais vantagens didáticas teria o GeoGebra em relação a estas outras plataformas? Segundo Solvang e Haglund [19],

não há muitos estudos sobre o uso do GeoGebra no ensino de física. Contudo, muitos deles defenderam o GeoGebra como um software que facilita as tarefas ativas dos alunos, que estimula os alunos a investigarem suas hipóteses e obterem respostas a perguntas que não poderiam ser respondidas empiricamente usando ferramentas tradicionais (Solvang e Haglund, p. 9670, 2018).

Acreditamos que essa vantagem reside essencialmente no objetivo principal do GeoGebra que é o ensino de matemática. Inúmeros são os relatos de professores de física que indicam que um dos principais problemas na aprendizagem de física, especialmente de mecânica, é a deficiência de seus alunos em matemática [20, 21]. Entretanto, possuir apenas habilidades técnicas em matemática, como o domínio instrumental de algoritmos, regras e fórmulas, não é suficiente para um aluno ter um bom desempenho em física [22]. Assim, um alto desempenho em matemática não é garantia para sucesso em física 23. Desta forma, "de muito pouco ou de quase nada, interessa a vivência isolada do aluno no contexto próprio da Matemática, sem um esforço específico de introduzi-lo na arte da estruturação do pensamento através da Matemática" [21]. Neste sentido, o GeoGebra é uma plataforma que melhor concilia a matemática com o ensino de ciências em uma perspectiva do estruturamento do pensamento, notadamente via modelagem matemática [24, 25, visto que ele promove nos alunos a possibilidade de modelar conceitos algébricos e geométricos, ou seja, de lidar com matemática pura, problemas de matemática e de ciências [26].

No intuito de apropriar determinados conteúdos de matemática que são indispensáveis para a aprendizagem de física (equações algébricas lineares, função quadrática, equações paramétricas, análise gráfica, teorema de pitágoras, funções trigonométricas, etc) numa perspectiva de transformar um saber em exercícios e problemas [27, o GeoGebra apresenta-se como um excelente recurso para a transferência destes conteúdos em problemas de física. Neste sentido, estudos têm demostrado sucesso quanto a aumentar a motivação e o interesse de alunos na aprendizagem de física. Recentemente, Tenório e Borges Neto [28] aplicaram o GeoGebra na resolução de problemas sobre o movimento retilíneo uniforme com o objetivo de transferir o conteúdo de funções e gráficos. Segundo os autores, os alunos destacaram como aspectos positivos desta experiência a melhor compreensão destes conteúdos, o aumento da concentração e a facilidade de usar o programa. Este último aspecto foi também observado por Solvang e Haglundem [19] em atividades investigativas sobre o atrito baseadas em uma simulação elaborada no GeoGebra. Estes últimos autores ainda concluiram que o GeoGebra propiciou uma experiência de descoberta por parte dos alunos através da análise do comportamento destes diante da tela dos computadores. Ainda, por meio de uma sequência de simulações elaboradas no GeoGebra, Malgieri e colaboradores [29] conduziram alunos em formação de professores em atividades de descoberta que tratavam de temas epistemológicos da natureza da luz adotando a formulação da mecânica quântica por integrais de caminho de Feynman. Segundo estes autores, o GeoGebra torna os modelos matemáticos por trás das simulações completamente transparentes, pois são facilmente acessíveis ao usuário.

Por fim, enumeramos abaixo alguns aspectos que fazem do GeoGebra um excelente recurso tecnológico para o ensino e a aprendizagem de física [18:

- gratuito, multiplataforma e dispõe de vários recursos fáceis de lidar;

- suporta cenários dinâmicos;

- permite salvar e exportar arquivos em diversos formatos;

- permite inserção de imagens;

- opera com Latex;

- dispõem de recurso de prova automatizado;

- dispõe de uma interface simples com o usuário;

- possibilita a produção de material didático que inclui planilhas dinâmicas autônomas e applets interativos;

- dispõe de uma comunidade internacional ativa de usuários que fornece suporte técnico e didático;

- disponibiliza ao usuário área personalizada em seu sítio eletrônico oficial com diversos recursos para divulgação de material didático;

- promove a formulação e expressão do pensamento matemático por meio de construções geométricas ou algébricas.

\section{O interferômetro de Michelson}

O experimento do interferômetro de Michelson-Morley é um dos mais importantes e célebres na História da Física. Entretanto, não nos deteremos demasiadamente em seu aspecto histórico, já que este experimento é abundantemente abordado em trabalhos de historiadores da ciência e ainda em livros acadêmicos de física (ver, por exemplo, 30 37]). Restringiremos aqui a apresentar um pequeno resumo do contexto histórico deste experimento.

Ainda que as famosas equações de Maxwel estabeleçam que a luz é uma onda eletromagnética, o próprio 
James Clerk Maxwell (1831-1879) levou bastante tempo para admitir este comportamento, pois mantinha firme uma concepção mecânica de que campos magnéticos eram vórtices giratórios em um fluido, o éter luminífero, em que pequeníssimas cargas transmitiam movimento de rotação a esses vórtices. Na hipótese da existência do éter, um raio de luz que percorresse para o leste deveria ser mais rápido do que outro que se movesse para o oeste, já que o éter teria um movimento relativo de oeste para leste em relação à Terra devido ao seu movimento de rotação em torno de seu eixo. Assim, a velocidade de propagação da luz seria a soma da velocidade própria da luz com a velocidade do meio de propagação, o éter. No entanto, a velocidade do éter em relação à Terra não teria nenhuma influência na velocidade de propagação da luz caso a luz percorresse a direção norte-sul. Isto posto, a velocidade do éter em relação à Terra poderia ser obtida pela diferença entre o tempo de propagação da luz ao propagar-se na direção leste-oeste e na direção norte-sul. Buscar esta diferença foi o propósito da experiência de A. A. Michelson e E. W. Morley em 1887 30 por meio de um interferômetro concebido para esse fim. Entretanto, esta experiência não indicou nenhuma diferença além da margem de erro do experimento: o efeito esperado deveria ser em torno de quatro vezes superior à precisão do aparato. Ressaltamos que, ainda hoje, refinamentos deste experimento ainda são realizados de modo a determinar esta diferença com maior precisão devido aos avanços tecnológicos de hoje 38 .

Ainda assim, com o objetivo de legitimar ou defender a teoria do éter, G. F. FitzGerald, em 1889, e H. A. Lorentz, alguns anos depois e de forma independente, sugeriram uma hipótese ad hoc na qual corpos ao se moverem através do éter simplesmente se contraíam em comprimento de modo que qualquer dispositivo seria impossibilitado de medir a velocidade relativa do éter. No caso do experimento de Michelson-Morley, o comprimento do caminho da luz ao longo da direção do vento do éter deveria contrair-se de um fator de $\sqrt{1-v^{2} / c^{2}}$. Lorentz estendeu estas correções também para o tempo e a massa, mas que implicava numa dilatação destas grandezas pelo fator $1 / \sqrt{1-v^{2} / c^{2}}$. No entanto, estas correções não trouxeram mudanças nas concepções de tempo e espaço existentes na época como aquelas que seriam propostas por A. Einstein em 1905, pois ainda prevalecia a concepção de referenciais absolutos para o tempo e o espaço.

Apesar de que Einstein deveria saber da experiência de Michelson-Morley, o segundo postulado de Einstein proposto em 1905 parece ter sido concebido mais em razão de suas especulações sobre a teoria eletromagnética de Maxwell e a velocidade da luz do que no fracasso do experimento de Michelson-Morley em observar a variação no tempo de propagação da luz entre caminhos perpediculares entre si. Com efeito, para Einstein, a existência do éter era uma concepção supérflua em que nada influenciaria nas implicações de sua teoria da relatividade especial.

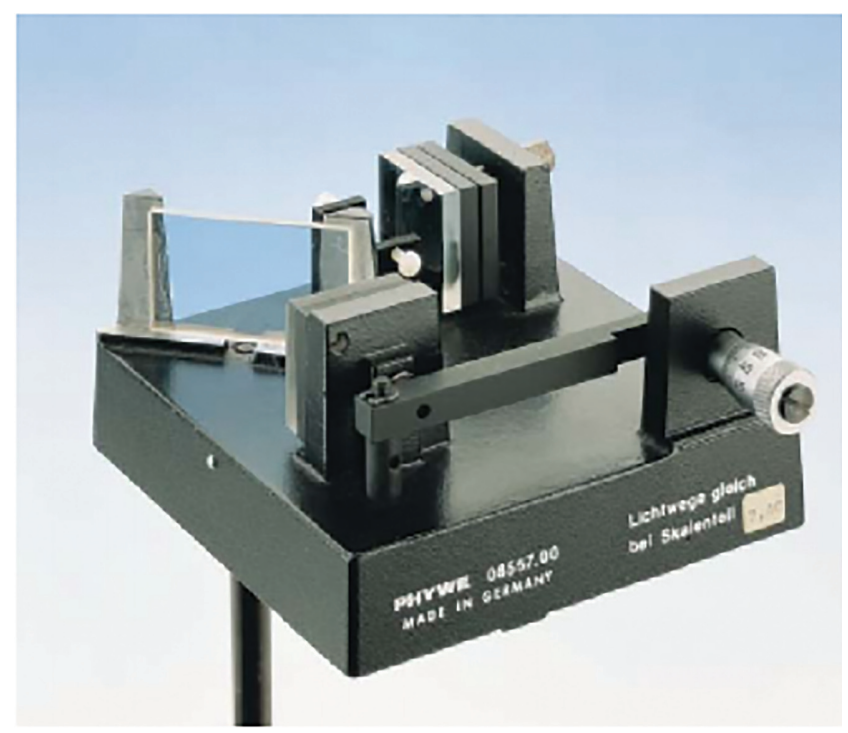

Figura 1: Interferômetro de Michelson produzido pela PHYWETM. Fonte: PLN CIÊNCIA

O interferômetro de Michelson, além de sua importância histórica, é um instrumento muito sensível que permite a determinação da variação de comprimentos menores do que um comprimento de onda da radiação eletromagnética utilizada. Assim, é utilizado em laboratórios de ensino de física para a determinação do comprimento de onda da luz e para a determinação dos índices de refração de gases. Vários fabricantes (PHYWE' ${ }^{\mathrm{TM}}$, PASCO ${ }^{\mathrm{TM}}$, Cidepe ${ }^{\mathrm{TM}}$ ) produzem interferômetros de Michelson voltados para o ensino de física. Entretanto, como não são equipamentos de custo acessível, não são encontrados comumente em laboratórios didáticos. Diante disto, propomos uma simulação elaborada no GeoGebra baseada no interferômetro de Michelson produzido pelo fabricante PHYWE ${ }^{\mathrm{TM}}$ (Figura 1).

\subsection{Determinação do comprimento de onda da luz}

Na Figura 2 está representado esquematicamente o interferômetro de Michelson; podemos ver que a luz de um laser incide em um espelho semitransparente e se divide em dois feixes. Um feixe é refletido em direção ao espelho 1 e o outro feixe é transmitido na direção do espelho 2. Os dois feixes são refletidos de volta e, dependendo da diferença de fase entre os mesmos, o grau de interferência será maior ou menor quando os dois feixes forem superpostos.

A introdução de uma lente convergente na saída do laser transforma o feixe em convergente, então as reflexões nos espelhes se comportarão como duas fontes de luz puntiformes. Na Figura 3 mostramos a formação de uma fonte p'. Parte do feixe convergente da luz que incide no espelho semitransparente é refletido em direção ao espelho 1 colocado à direita. $\mathrm{O}$ feixe convergente ao 


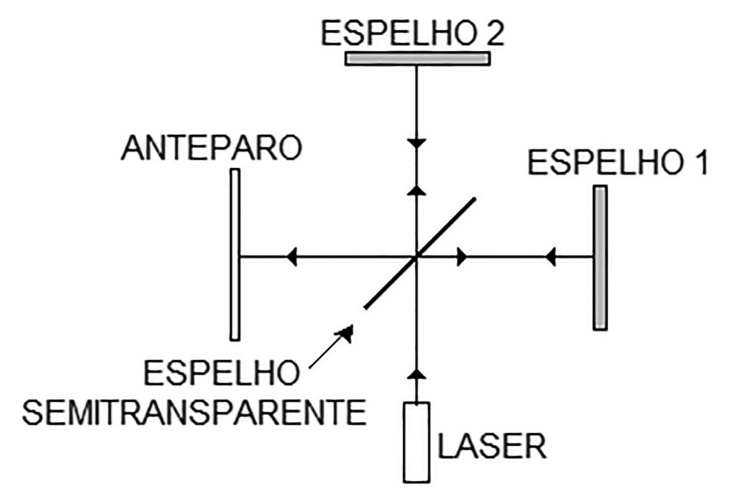

Figura 2: Representação esquemática do interferômetro de Michelson.

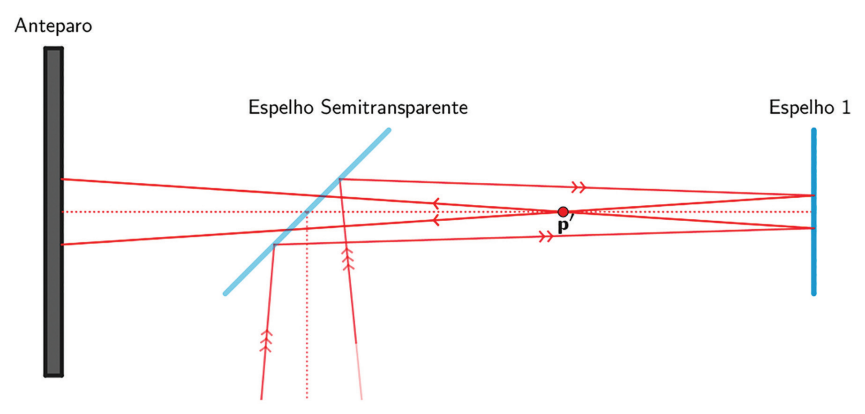

Figura 3: Formação da fonte de luz divergente p'.

ser refletido neste espelho converge para o ponto p' que se comporta como uma fonte puntiforme de luz que se propaga em direção ao anteparo.

$\mathrm{Na}$ Figura 4 mostramos a formação da fonte $\mathbf{p}$ ". A outra parte do feixe convergente da luz que incide no espelho semitransparente é transmitida em direção ao espelho 2 colocado acima. $\mathrm{O}$ feixe convergente ao ser refletido neste espelho converge para um ponto $\mathbf{p}$ e se propaga em direção ao espelho semitransparente. Ao ser refletido no espelho semitransparente em direção ao anteparo, o prolongamento da luz refletida determina o ponto p" (imagem virtual do ponto $\mathbf{p}$ formada pelo espelho semitransparente), que se comporta como uma segunda fonte puntiforme de luz, p".

As duas fontes de luz, p' e p" (ver Figura 5) de mesmo comprimento de onda $\lambda$ e em fase, produzirão no centro do anteparo um máximo na intensidade luminosa toda vez que a diferença de caminho $X$ for igual a um número inteiro de comprimento de onda, assim:

$$
\mathbf{X}=m \lambda, \quad m=1,2,3 \ldots
$$

Deslocando-se um dos espelhos com um parafuso micrométrico, enquanto o outro permanece fixo, observaremos no centro do padrão de interferência projetado no anteparo uma alternância entre interferências construtivas e destrutivas. Uma nova interferência construtiva é observada toda vez que o espelho se desloca de uma distância $\ell=\lambda / 2$, pois a cada deslocamento do espelho de $\ell$ corresponde a um deslocamento $2 \ell$ da fonte de

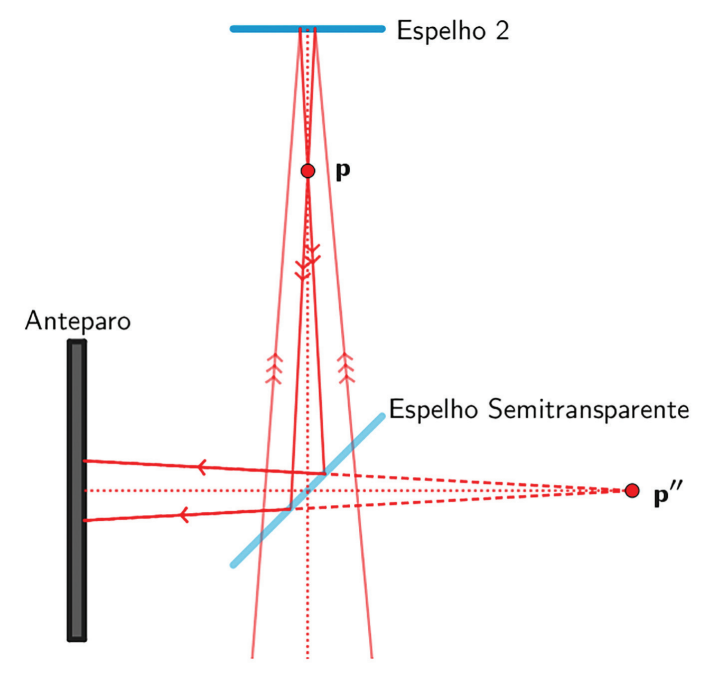

Figura 4: Formação da fonte de luz divergente p".

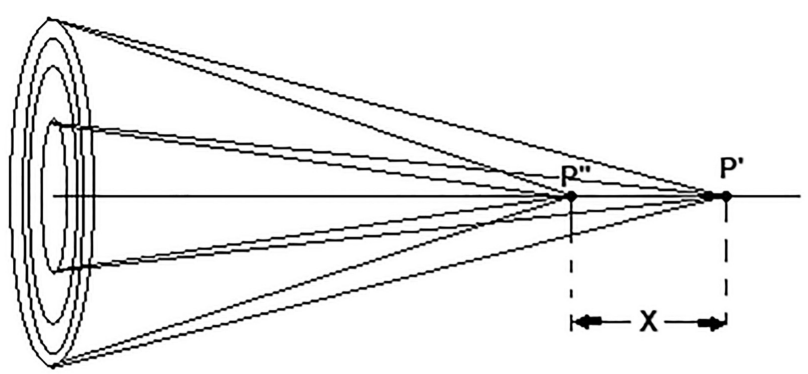

Figura 5: Representação das fontes de luz, p' e p", geradas pelas reflexões nos espelhos do interferômetro.

luz p'. Desta forma, deslocando o espelho lentamente e contando-se um grande número de repetições de interferências construtivas no anteparo é possível determinar o comprimento de onda da luz no ar.

Devido à presença da lente convergente, cada fonte virtual produzirá um feixe de luz cônico. Assim, devido às diferenças de fase entre os raios que chegam ao anteparo, haverá a formação de círculos claros de interferências construtivas e círculos escuros de interferências destrutivas.

Para aumentar a sensibilidade do interferômetro, o parafuso micrométrico empurra uma alavanca que, por sua vez, empurra o espelho móvel numa razão de 10:1 (tanto no interferômetro da PHYWE ${ }^{\mathrm{TM}}$ como no interferômetro da simulação). Desta forma, para um deslocamento do parafuso micrométrico de $\Delta s$, teremos um deslocamento do espelho de $\Delta s / 10$ e o dobro deste valor $(\Delta s / 5)$ da fonte $\mathbf{p}$ ", ou seja, da imagem refletida no espelho. Se um deslocamento $\Delta s$ implica em $m$ alternâncias entre interferências construtivas consecutivas, da Equação 1 temos que:

$$
\Delta s=5 m \lambda, \quad m=1,2,3 \ldots
$$

Assim, $\Delta s=5 \lambda$ para $m=1$. 


\subsection{Determinação do índice de refração de um gás}

O índice de refração $n$ de um gás nobre depende linearmente com a pressão de acordo com a relação de Hauf-Grigull [39]:

$$
n(p)=1+k p,
$$

onde $p$ é a pressão e $k$ uma constante que depende do gás e da temperatura. Para o vácuo absoluto, $p=0 \mathrm{e}$, portanto, $n(0)=1$. Por outro lado, o caminho ótico da luz, $\mathrm{X}$, é dado por

$$
\mathrm{X}=n(p) \mathrm{L}_{\mathrm{o}},
$$

onde $L_{o}$ é a espessura interna de uma célula de vidro que contém um gás (ver Figura 6), e será percorrida pela luz $\left(\mathrm{L}_{\mathrm{o}}=10 \mathrm{~mm}\right)$.

Para determinar o índice de refração do gás, diminuise a pressão na célula de vidro $(\Delta p<0)$ e observase uma alternância no padrão de interferência como consequência da variação do caminho ótico X. Agora, com a célula de vidro, o deslocamento da fonte de luz virtual é devido à variação do caminho ótico $\Delta \mathrm{X}$. Assim, da Equação 4 e da Equação 1, temos:

$$
\Delta \mathrm{X}=\Delta n(p)\left(2 \mathrm{~L}_{\mathrm{o}}\right)=-m \lambda, \quad m=1,2,3 \ldots
$$

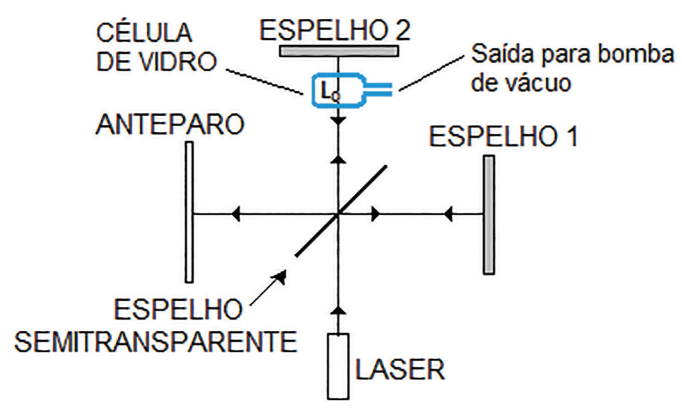

Figura 6: Representação esquemática do interferômetro de Michelson com célula de vidro. onde $2 \mathrm{~L}_{\mathrm{o}}$ representa a distância percorrida pela luz dentro da célula de vidro, levando-se em consideração o percurso de ida e de volta, e $m$ é o número de alternâncias do padrão de interferência como mencionado acima. Note que, para uma variação de pressão para valores cada vez menores, o índice de refração do gás diminui $(\Delta n<0)$, daí o sinal negativo na Equação 5 para contarmos um número positivo de $m$. Ao combinarmos a Equação 3 e a Equação 5 temos:

$$
k=-\frac{m \lambda}{2 \mathrm{~L}_{\mathrm{o}} \Delta p}, \quad m=1,2,3 \ldots
$$

Desta forma, registrando-se a variação da pressão que ocorre para que sejam observados $m$ ciclos completos de alternância no padrão de interferência, podemos determinar $k$. Para determinar o índice de refração de um gás basta então substituir os valores de $k$ e $p$ (pressão atmosférica) na Equação 3 Consideraremos que, na simulação, a pressão inicial é sempre a pressão de $1 \mathrm{~atm}$, que corresponde a 1,013 bar.

\section{A Simulação}

Na Figura 7 podemos ver a tela inicial da simulação. Nela, o interferômetro está representado visto de cima. Um parafuso micrométrico digital substitui o micrômetro analógico presente no interferômetro real. Podemos ver ainda a fonte de luz laser e uma lente convergente bem em frente da saída da fonte de luz. Podemos ver também uma bomba manual de vácuo utilizada nos experimentos para medidas dos índices de refração de gases.

Ao clicar em Ligar/Desligar Laser, a simulação mostra três opções de cores (da luz do laser) e aparece um botão Visualizar Trajetória da luz. Ao clicar neste último botão, a simulação apresenta uma pequena animação em que um ponto luminoso, saindo do laser, se desloca até encontrar o espelho semitransparente. Ao atingir esse espelho, o ponto luminoso se divide em dois pontos menores, sendo que um dos pontos é refletido para a

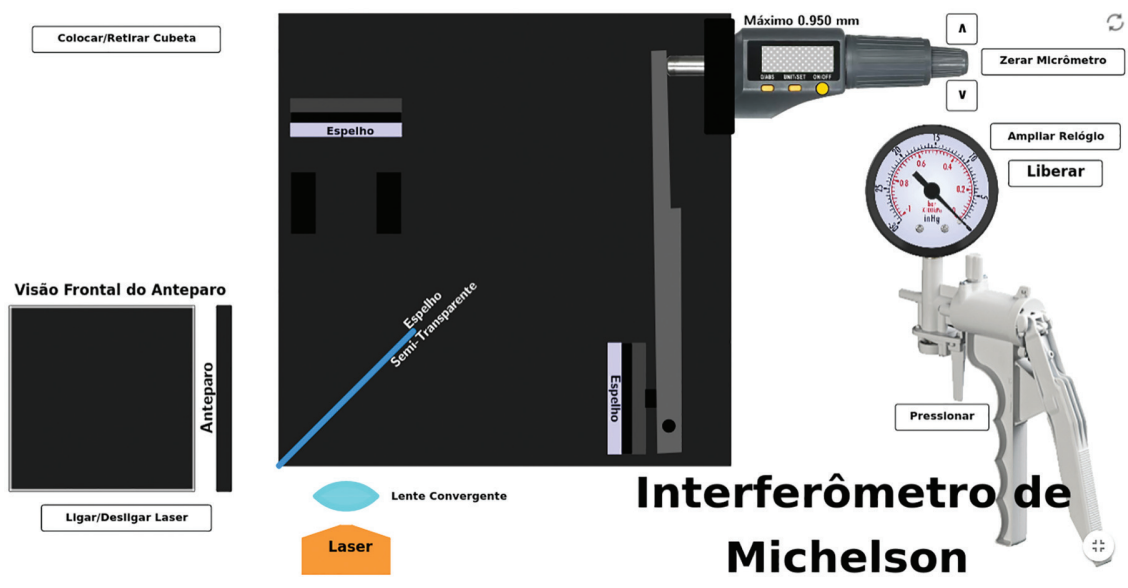

Figura 7: Tela inicial da simulação do interferômetro de Michelson. 


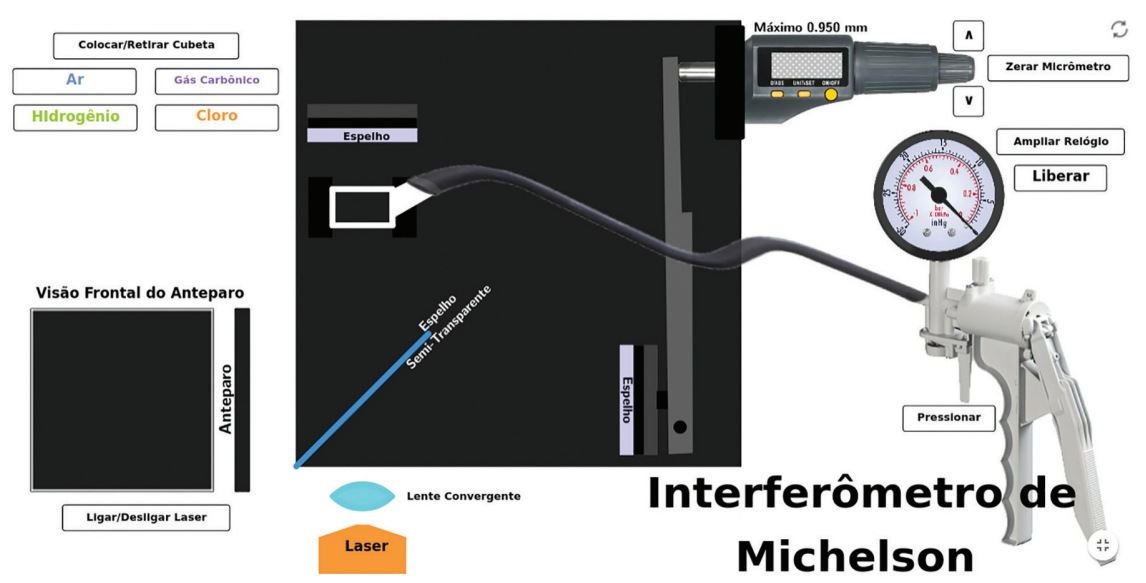

Figura 8: Tela da simulação do interferômetro de Michelson para medir o índice de refração do gás a ser selecionado.

direita, atinge o espelho colocado à direita e reflete de volta em direção ao anteparo. O outro ponto atravessa o espelho semitransparente, atinge o espelho à frente, e reflete de volta em direção ao espelho semitransparente. Ao chegar no espelho semitransparente, este ponto é refletido para a esquerda em direção ao anteparo. Os dois raios de luz (os dois pontos luminosos, na simulação) se sobrepõem no anteparo onde haverá interferência que, a depender da diferença de caminho percorrido, poderá ser destrutiva, parcialmente construtiva ou construtiva.

Ao clicar em Colocar/Retirar Cubeta, uma cubeta (célula de vidro) é posicionada em frente ao espelho superior. Essa cubeta se liga à bomba de vácuo por uma mangueira. Da mesma forma aparecem opções de seleção, agora de quatro tipos de gases. Ao clicar em Ampliar Relógio podemos ver o mostrador da bomba de vácuo ampliado de modo a facilitar as leituras. A Figura 8 mostra a tela da simulação após realizados os procedimentos descritos acima.

O ponto circular amarelo no micrômetro liga e desliga o mesmo. As setas para cima e para baixo, próximas ao micrômetro, permitem a rotação do parafuso micrométrico no sentido de avançar ou retroceder, respectivamente. Na simulação há um limite máximo de 0,950 mm na leitura do micrômetro. Este limite não compromete em nada as medidas que podem ser simuladas. O botão Pressionar aciona a bomba de vácuo; o botão Liberar restaura a pressão inicial de 1,013 bar. As setas semicirculares no canto superior direito permitem reiniciar a simulação.

\subsection{Determinação do comprimento de onda da luz}

Para a determinação do comprimento de onda da luz, após escolher o laser da cor desejada e ligar o micrômetro digital, o usuário deverá acionar o micrômetro, repetidas vezes, enquanto observa a evolução do padrão da figura de interferência que pode ser visualizada no anteparo em Visão Frontal do Anteparo. Para minimizar os erros "experimentais", recomendamos aos usuários que observem uma sequência de pelo menos 20 ciclos e que repita a medida algumas vezes, e começar preferencialmente em fases diferentes da figura de interferência, de modo que as medidas subsequentes não sejam influenciadas pelos valores obtidos anteriormente. Os resultados obtidos, assim como ocorre no experimento real, apresentam pequenos erros experimentais, principalmente devido à dificuldade de reconhecer o momento exato em que um ciclo se completa em relação à configuração inicial. Ao anotar o valor do deslocamento do micrômetro $(\Delta s)$ para completar os 20 ciclos $(m=20)$ observados e ao substituir estes valores na Equação 2 é possível determinar o comprimento de onda da luz em investigação.

\subsection{Determinação do índice de refração de um gás}

Para a determinação do índice de refração de um dos gases (ar, gás carbônico, hidrogênio ou cloro), o usuário deverá clicar em Colocar/Retirar Cubeta e escolher o gás que deseja determinar o índice de refração. Deverá clicar em Pressionar repetidas vezes enquanto observa a evolução do padrão da figura de interferência. Sugerimos observar uma sequência de pelo menos dez ciclos (quando possível). Deve-se anotar a variação de pressão verificada $(\Delta p)$ correspondente ao número de ciclos $m$. Ao substituir estes valores na Equação 6 para a determinação de $k$ e em seguida utilizar a Equação 3 é possível determinar o índice de refração do gás na pressão desejada.

As medidas de variação de pressão não são suficientemente precisas de modo a discriminar os valores dos índices de refração para as diferentes cores. Também recomendamos aos usuários que repitam as medidas algumas vezes de modo a minimizar os erros nos resultados (experimentais). Na simulação consideramos que a relação válida para gases nobres, Equação 3 também é válida para os demais gases para os intervalos de variação de pressão simulados. 
A simulação aqui apesentada está disponível na página do Departamento de Física da Universidade Federal do Ceará: www.laboratoriovirtual.fisica.ufc.br/interferome tro-de-michelson Nesta mesma página, há uma sugestão de roteiro de prática para guiar o usuário na execução dos experimentos e nas análises dos mesmos.

\section{Considerações Finais}

O GeoGebra é um programa que permite, além de construções geométricas, confecção e estudo de gráficos, manuseio de planilhas, dentre outros recursos, a elaboração de simulações interativas que podem ser usadas tanto pelo professor para ilustrar suas aulas como em experimentos virtuais. Embora reconheçamos que uma simulação não seja equivalente a um experimento real, a simulação do interferômetro de Michelson aqui apresentada pode mitigar com vantagens, em alguns aspectos (uso de diferentes cores de luz, possibilidade de utilização de diversos gases, utilização individual pelo aluno, utilização sem restrição ao horário da prática), o experimento real usado em laboratórios de ensino de física. Nossas observações do uso pelos nossos estudantes durante o isolamento social no segundo semestre de 2020 e primeiro semestre de 2021 nos levam a afirmar que a compreensão do funcionamento do interferômetro e a fixação dos conceitos trabalhados no experimento não apresentam uma perda pedagógica em relação ao experimento realizado presencialmente antes da pandemia. Não realizamos um estudo comparativo entre o experimento real e a simulação, mas os relatórios produzidos pelos alunos, baseado no roteiro do experimento real, apenas adaptado para o uso da simulação e contendo praticamente o mesmo questionário, nos mostram que os alunos compreenderam bem o funcionamento do mesmo e os fenômenos físicos envolvidos. No primeiro semestre de 2021, colegas nossos passaram a utilizar a simulação em suas turmas, nos diversos polos do curso de licenciatura em física semipresencial ofertado pela UFC, com boa aceitação por parte dos alunos. Com a volta das atividades presenciais em laboratórios didáticos, pensamos em usar esta e outras simulações elaboradas no GeoGebra como atividades preparatórias para atividades com experimentos reais. Com efeito, impactos positivos foram encontrados na compreensão de tarefas em laboratório, bem como de habilidades práticas de laboratório durante atividades em laboratório real quando simulações são utilizadas como treinamento pré-laboratório [40].

A manipulação de um experimento real contribui significamente para a consolidação do conhecimento em si, e o GeoGebra possui inúmeras ferramentas geométricas com as quais vários sistemas podem ser simulados. Deste modo, por meio desse programa, é possível transcrever, tanto qualitativa como quantitativamente, as características estruturais e físicas compatíveis com o cenário encontrado em laboratório, sendo visível e manipulável atráves de sua zona gráfica. Com isso, cuidadosamente, há como proporcionar ao aluno sensações similares às esperadas com o uso do equipamento real. Para o caso do interferômetro de Michelson apresentado, a representação do micrômetro e o custo para que o giro da catraca desloque o braço da alavanca para que haja o deslocamento do espelho acoplado, desenvolve a percepção da diferença da ordem de grandeza entre o sistema e o comportamento físico analisado (interferência da luz através dos arranjos dos espelhos e, caso incluído, da presença de gás no caminho seguido pela luz). Diversas animações e simulações relacionadas estão disponíveis online, mas estas são apenas esquemáticas, carentes de detalhes laboratoriais que tornam possível a formação do padrão de interferência com simetria circular, pouco realísticas e incompletas, apresentando apenas a relação com o comprimento da luz, sem mencionar a possibilidade de determinar o índice de refração de um gás. Além disso, muitas são desatualizadas, dependentes de plugins ou programas de terceiros, ou de difícil acesso.

Esperamos que este trabalho promova o uso do GeoGebra por professores de física e o debate na comunidade de pesquisa em ensino de ciências a respeito de seus aspectos pedagógicos como recurso digital. Vários trabalhos acadêmicos foram publicados sobre o uso do programa Modellus neste sentido. No entanto, apesar de ter-se mostrado um excelente recurso de modelagem voltado ao ensino, este ambiente de modelagem encontrase descontinuado há anos sem que haja atualizações e contribuições da imensa comunidade que ainda o utiliza como recurso educacional. Certamente, a difusão do GeoGebra no meio da comunidade de professores de física em todos os níveis de ensino promoverá valiosas contribuições a adaptações deste programa cada vez mais voltadas à modelagem de processos físicos.

\section{Referências}

[1] C.E. Wieman, W.K. Adams e K.K Perkins, Science 322, 5902 (2008).

[2] J. Maloney, M. Resnick, N. Rusk, B. Silverman e E. Eastmond, ACM Transactions on Computing Education 10, 4 (2010).

[3] W. Christian e F. Esquembre, The Physics Teacher 45, 475 (2007).

[4] J.S. Figueira, Revista Brasileira de Ensino de Física 27, 4 (2005).

[5] V.D. Teodoro, Modellus: Learning Physics with Mathematical Modelling. Tese de Doutorado, Universidade Nova de Lisboa, Lisboa (2002).

[6] I.S. Araújo, E.A. Veit e M.A. Moreira, Revista Brasileira de Ensino de Física 26, 2 (2004).

[7] https://www.geogebra.org/a/14.

[8] https://www.youtube.com/user/GeoGebraChannel

[9] https://www.geogebra.org/materials.

[10] https://www.geogebra.org/u/tomwalsh

[11] T. Walsh, The Physics Teacher 55, 316 (2017). 
[12] O. Skovsmose, Bolema 13, 14 (2000).

[13] M.A. Gravina e L.M. Santarosa, Informática na Educação: teoria \& prática. 2, 1 (1999).

[14] https://www.geogebra.org.

[15] A.G.M.F.F. Voltolini, Na palma da mão: a difusão de celulares e smartphones e possibilidades para o ensinoaprendizagem no Brasil. Tese de Doutorado, Universidade Metodista de São Paulo, São Paulo (2016).

[16] J.A. Macêdo, A.G. Dickman e I.S.F. Andrade, Cad. Bras. Ens. Fís. 29, 1 (2012).

[17] https://www.geogebra.org/notes.

[18] Y.A. Wassie e G.A. Zergaw, North American GeoGebra Journal 7, 1 (2018).

[19] L. Solvang e J. Haglund, em: Proceedings of EDULEARN18 Conference (Palma, 2018).

[20] A.B. Champagne, L.E. Klopfer e J.H. Anderson, American Journal of Physics 48, 12 (1980).

[21] M. Pietrocola, Cad. Cat. Ens. Fís. 19, 1 (2002).

[22] R.A.S. Karam e M. Pietrocola, Alexandria: Revista de Educação em Ciência e Tecnologia 2, 2 (2009).

[23] H.T. Hudson e W.R. McIntire, American Journal of Physics 45, 5 (1977).

[24] C.O. Lozada, M.S.T. Araújo, W. Marrone e L.H. Amaral, Revista Logos 14, 2 (2006).

[25] J. Hall e T. Lingefjärd, Mathematical Modeling: Applications with GeoGebra (Wiley, Hoboken, 2017).

[26] M. Milner-Bolotin, Canadian Journal of Science, Mathematics and Technology Education 16, 3 (2016).

[27] J.P. Alves Filho, Caderno Catarinense de Ensino de Física 17, 2 (2000).

[28] A. Tenório e A.C. Borges Neto, Revista do Instituto GeoGebra de São Paulo 8, 1 (2019).

[29] M. Malgieri, P. Onorato e A. De Ambrosis, European Journal of Physics 35, 5 (2014).

[30] A.A. Michelson e E.W. Morley, Philosophical Magazine S. 24, 151, (1887).

[31] R.S. Shankland, Amer. J. Phys. 32, 16 (1964).

[32] R.C. Miranda Filho, Base experimental e teoria em Física: uma análise do experimento de Michelson $e$ Morley. Tese de Doutorado, Universidade do Estado de São Paulo, São Paulo (2004).

[33] A. Barros, E.M. Monte, I.G. Araújo, J.C.T. Oliveira e S. Vieira, Revista Brasileira de Ensino de Física 27, 4 (2005).

[34] F.L. da Silveira e L.O.Q. Peduzzi, Cad. Bras. Ens. Fís. 23, 1 (2006).

[35] P.A. Tipler e R.A. Llewellyn, Física Moderna (LTC, Rio de Janeiro, 2010).

[36] A. Chaves, Física (Reichmann \& Affonso Editores, Rio de Janeiro, 2001), v. 3.

[37] G. Holton e S.G. Brush, Physics, the Human Adventure: From Copernicus to Einstein and Beyond (Rutgers University Press, New Brunswick, 2001).

[38] G.G. Nyambuya, Journal of Morden Physics 5, 12 (2014).

[39] W. Hauf e U. Grigull, Adv. Heat. Transf. 6 (1970).

[40] N. Rutten, W.R. van Joolingen e J.T. van der Veen, Computers \& Education 58, 1 (2012). 